\title{
The Oxford Service for the Young Adult Chronically Mentally Ill
}

\author{
G. P. Pullen, Consultant Psychiatrist, Littlemore Hospital, Littlemore, Oxford OX4 4XN
}

Oxfordshire is a pleasant, prosperous county dominated by the City where about one third of its 480,000 population lives. Oxford itself has nearly 15,000 students attending the University or Polytechnic. The active rehabilitation of longstay patients was started in Oxford over 25 years ago, with the result that by 1986 there were only 40 non-dementing psychiatric-in-patients with a current admission of five or more years. This successful programme of rehabilitation, now virtually completed, was achieved by creating a wide range of sheltered work and other activities, and by the provision since 1963 of over 40 group homes and hostels by the Oxford Group Homes Organisation. However, many psychiatric illnesses still have a chronic and relapsing course; $65 \%$ of all admissions, aged 18 to 65 to the Oxford District mental illness units in 1982 and 1983, were readmissions. For those diagnosed as suffering from schizophrenia the figure rises to $80 \%$. In 1972 and 1973 Mann \& Cree $^{1}$ surveyed 400 'new' long-stay patients (current admission one to five years, aged 18 to 65) in 15 hospitals in England and Wales. They found a rate of 25 per 100,000 population and concluded that for about one third continuing hospital care was the only realistic option. If the remainder were to leave hospital, hostels providing a high level of support would be needed. The recent 1982 survey of 'new chronic' in-patients in 14 Scottish psychiatric hospitals still showed a rate of 17.2 per 100,000 population, of whom only $38 \%$ were not thought to be in need of continuing hospital care. ${ }^{2}$

Hospital hostels In three districts the DHSS released special funds in order to create 'hospital hostels' as recommended by Mann \& Cree. The first hostel-ward, 111 Denmark Hill, was opened in 1977 in a large Victorian house on a corner of the Maudsley Hospital site. The ward admitted 13 of the 29 patients who had accumulated from Camberwell since 1970, who were aged 18-65, and had been in hospital for between one and seven years. "The hostel-ward was intended to provide a domestic-scale environment", and to allow the residents more personal freedom than a traditional psychiatric ward. However, laundry and catering services continued to be provided by the hospital. At the beginning of 1979 all but two residents left the hostel during the week days to attend at one of a variety of local centres.

In 1982 Douglas House was opened in Manchester in another detached Victorian house. By the end of 1984 it had admitted 16 of the 20 patients with hospital stays of six months or more who had been generated since 1971 by the new University Hospital of South Manchester. ${ }^{3}$ Douglas House owes part of its inspiration to 111 Denmark Hill and shares with it, "treatment programmes designed for each resident by a psychologist", a reward points system being used. Douglas House, however, is a mile from the parent hospital and the patients' programmes are based upon living skills practised in the hostel itself: shopping, cooking, cleaning, laundry. There are no domestic or catering staff.

The third hospital hostel, Cranbury Terrace, is a few hundred yards from the Royal South Hants Hospital in two converted four-storey houses. When it opened in 1984 it admitted over the first eight months 20 of those 28 patients from its district who had been in hospital from one to five years and who were aged $16-64 .^{4}$ In some ways the programmes of Cranbury Terrace lie midway between the other hostels; patients can attend activities outside the house but there is an occupational therapist attached to the unit. Some cooking and other domestic tasks are carried out by the residents but there are, for example, two kitchens, one of which can be used only by the catering staff. All three hostel-wards are, with justification, considered to be successful experiments, although with their high level of staffing they are not cheap.

The Young Adult Unit In 1980 all Oxfordshire's consultant psychiatrists were invited to refer new patients to the then Marlborough Rehabilitation Unit. Unlike the three hostel-wards described above, no conditions were laid down regarding previous length of admission as it should be possible to identify clinically those patients particularly at risk. ${ }^{5}$ Suitable patients were required instead to have been diagnosed as suffering from a psychotic illness or severe personality disorder, to be of "normal" intelligence (IQ $>70$ ), and to have residual "social disability". The concept of "social disablement" is of central importance and is described as caused by:

"1. psychiatric impairments or dysfunctions (often described as 'symptoms')

2. social disadvantages

3. personal reactions to impairment or disadvantages, or to a combination of both".

By 1985 nearly 200 referrals had been received, of whom about two-thirds were accepted. The latter included ten patients admitted from the Special Hospitals. On closer examination, the "new long-stay" was revealed to contain at least two distinct clinical groups (see also ${ }^{4}$ ). There is a middle-aged (45-65 years) sub-group who have a long hospital history and who, for one reason or the other, have not been able to cope as well as their resettled contemporaries. In 1980 a 13- bedded 'hospital hostel', Coombs View Hostel, was opened within Littlemore Hospital for this group. The residents continued to receive all hospital 
services, but there were only three nurses attached to the unit, and only 'night patrolling'. In general the needs of this group (the 'old long-stay'?) are the same as those patients whose rehabilitation did lead to successful resettlement in the community. Oxford's Sheltered Workshops and day centres, therefore, serve both in-patients and out-patients.

In summer 1980 Ward B5, Littlemore Hospital, housed a mixed sex group of 23 'medium dependency' patients aged 23 to 81 . A few years previously the ward had been a 'male disturbed' unit and many of its former residents remained. It was housed on the first and second floors of a particularly poor wing of Littlemore (designed by the same Victorian architects as Oxford Prison), and had, for example, only dormitory accommodation. Nevertheless new patients were admitted, the ward renamed the Eric Burden Community (EBC), and a therapeutic community programe developed. A typical new referral was a young man in his early twenties who first caused concern with problems at school. By his late teens he had had his first admission to a psychiatric hospital with clear symptoms of a schizophrenic illness. His response to medication would have been partial and he will have had a couple of relapses and admissions before referral (i.e. early onset and poor response to neuroleptics). ${ }^{5}$ This typical young man has confused parents who desperately try to talk him into behaving acceptably (i.e. he lives in an environment of high expressed emotion, EE). He may well have experimented with a variety of drugs and may be abusing any anticholinergics prescribed. Both he and the acute admission ward staff caring for him may be despondent as a result of this 'failure' to get better (i.e. handicaps from 'personal reactions to impairment'). ${ }^{6}$

The EBC treatment programme matches Wing's three components of social disablement. Firstly, the staff have considerable experience in the medical treatment of psychosis. Secondly, the EBC is a therapeutic community employing an explicit social psychiatric approach. We believe that the therapeutic community is a particularly appropriate treatment method, making it possible to steer a middle course between environmental poverty, understimulation and institutionalisation on the one hand, and over-critical intrusion such as seen in high EE families on the other. Finally all patients are members of one of two weekly small groups, whilst some in addition receive individual psychotherapy. An attempt is also made to maintain the balance between communal activities and individual programmes. In the early years the emphasis was upon the resident leaving the ward in order to pursue some activity elsewhere in the hospital. Increasingly, however, the emphasis has shifted toward ward-based activities, especially those involving daily living skills (cf. Douglas House). The EBC moved to a detached refurbished 24-bedded (15 male, 9 female) modern building on the edge of the Littlemore Hospital site in autumn 1986 and the residents now cook every evening meal (having earlier done the shopping). Residents also help in keeping the ward clean and are responsible for their individual laundry. It would be legitimate, therefore, to call the new EBC another "hospital hostel', but we prefer to continue to call it a 'community'.
Every patient also has an individual programme planned by the use of the Marlborough Assessment Procedure (MAP) developed in the Unit. Like the nursing process, the MAP involved the steps of assessment, formulation, implementation of intervention plans, and finally, evaluation and reassessment, but it is multidisciplinary and, we believe, more flexible. One particular feature is that a patient's assets as well as his handicaps are assessed. The EBC at the time of writing has less than two nurses for every three patients and no occupational therapist. This level of staffing is obviously insufficient, being less even than the hostels described above, and has resulted in shortfalls in the treatment programme. Nevertheless every patient's family is offered support, including membership of a discussion group.

The newly admitted resident spends between a few weeks and a few years in the EBC, typically just under one year. Many patients then move onto the other residential facility within the Young Adult Unit (YAU), Thorncliffe House Half-Way Hostel, a ten-bedded Edwardian house in North Oxford. This hostel has three nursing staff but no resident night cover. Residents are expected to go out to 'work' during the day, and to spend no more than six months in the hostel before moving on. Many attend a Day Centre ('The Mill') run by Oxford MIND specifically for the young chronically mentally ill. Patients are then usually discharged to a group home or other accommodation, but they are not discharged from the yaU Case Register and they continue to be followed up by the YAU team. Young Adult Unit patients are encouraged to come to the EBC at any time if they have either psychiatric or social problems. Few barriers are erected against readmission, and the EBC acts as an acute admission ward for its own patients. (A sample in 1984 of 25 such readmissions showed an average length of stay of 11.6 days).

\section{Comment}

A number of local factors highlighted the needs of the "new long-stay' in Oxford. The young, growing population and the influx of many students increases the group liable to the onset of schizophrenia, although the numbers of first admissions (diagnosis ICD 295 \& 297) are not excessive: 70 in 1982, 46 in 1983 (Oxford Record Linkage Study) equivalent overall to 12 per 100,000 per annum. Before 1980 those inpatients who did not respond to treatment, however, tended to remain "blocking" acute beds because of the very few long-stay beds available. It has been demonstrated that the average length of stay in an acute unit can be reduced to 16 or 17 days with no apparent ill effects for the patient and with no increase in the readmission rates. Hirsch ${ }^{7}$ has pointed out the very considerable cost savings of so running acute services, but also that "... small changes in the number of longer staying patients have an enormous effect on the number of beds used and the potential turnover capability of the unit". A third Oxford factor was the decision in 1976 not to open a Regional Secure Unit but to contain such patients in the local hospitals. In Oxforshire all psychiatric units are open and there are no secure units or 
disturbed wards to contain (and conceal) any of the chronically mentally ill. By 1980 , therefore, the generation of potential new long-stay patients was particularly visible in Oxford and the service described above was created. As its primary aim is to prevent patients becoming long-stay and institutionalised the term "young adult chronic patient" was borrowed from the United States, rephrased as the "young adult chonically mentally ill".

\section{REFERENCES}

'MANN, S. A. \& CREE, W. (1976) 'New' long-stay psychiatric patients: A national sample survey of fifteen mental hospitals in England and Wales 1972/3. Psychological Medicine, 6, 603-616.

${ }^{2}$ McCreadie, R. G., Wilson, A. O. A. \& Burton, L. L. (1983) The Scottish survey of 'new chronic' in-patients. British Journal of Psychiatry, 143, 564-571.
${ }^{3}$ Goldberg, D. P., Bridges, K. CoOper, W., Hyde, C., Sterling, C. \& WYATT, R. (1985) Douglas House: A new type of hostel ward for chronic psychotic patients. British Journal of Psychiatry. 147, 383-388.

${ }^{4}$ GibBons, J. S. (1986) Care of 'new' long-stay patients in a District General Hospital psychiatric unit: The first two years of a hospital-hostel. Acta Psychiatrica Scandinavica. 73, 582-588.

${ }^{5}$ Kolakowska, T., Williams, A. D., Arden, M., Reveley, M. A., JAMbOR, K., Gelder, M. G. \& MANDflbrote, B. M.(1985) Schizophrenia with good and poor outcome: (1) Early clinical features, responses to neuroleptics and signs of organic dysfunction. British Journal of Psychiatry, 146, 229-239.

${ }^{6}$ WING, J. K. \& MORRIS, B. (1981) Handbook of Psychiatric Rehabilitation Practice. Oxford: Oxford University Press.

${ }^{7} \mathrm{HIRSCH}$, S. R. (1983) Bed requirements for acute psychiatric units: the concept of a norm. The Bulletin of the Royal College of Psychiatrists, 7, 118-122.

\section{Conference Report}

\section{International Symposium on Dermatology and Psychiatry, Vienna, 1987}

An International Symposium on Dermatology and Psychiatry was held in Vienna from 29 May to 2 June 1987 under the auspices of the Association of European Psychiatrists and hosted by the Psychiatric University Clinic in Vienna. The organisation was largely the inspiration of Professor Peter Berner, Head of the University of Vienna Department of Psychiatry and of Dr John Cotterill, consultant dermatologist, the General Infirmary at Leeds. The symposium was a pioneering effort but proved very successful, and approximately 100 papers were presented.

The topics were wide-ranging and reflected the many points of contact between psychiatry and dermatology. On the first day there were presentations on infestational delusions, alopecia, urticaria and eczema, and on the second day we heard about factitious skin disorders, psoriasis, tattooing, hypochondriasis, dysmorphophobia and AIDS. A number of papers reviewed aspects of consultation-liaison psychiatry and reflected a clear desire by dermatologists for sound, commonsense psychiatric opinions on a significant proportion of their cases.

The principal language was English, but papers were also given in German and French. On the whole communication was good, presentations were relevant and discussions were lively. A number of valuable original reports were given, and while a few psychiatrists diverted on to woolly psychopathological speculations to the dismay of the dermatologists, this was the exception. In general, psychiatry showed up well and the consensus was that the symposium was a successful exercise in interdisciplinary communication and perhaps a significant first step in developing common concepts and jargon in order to deal with the many patients the two specialties share.

Psychodermatology appears at present to be a developing field for liaison. Because of the positive response to this symposium it is hoped to follow up with a second one in 1989, possibly in Cambridge. The organising committee will give plenty of advance notice to the psychiatric and the dermatological journals when the preliminary details have been settled.

Department of Psychiatry

Alistair Munro

Halifax, Nova Scotia 